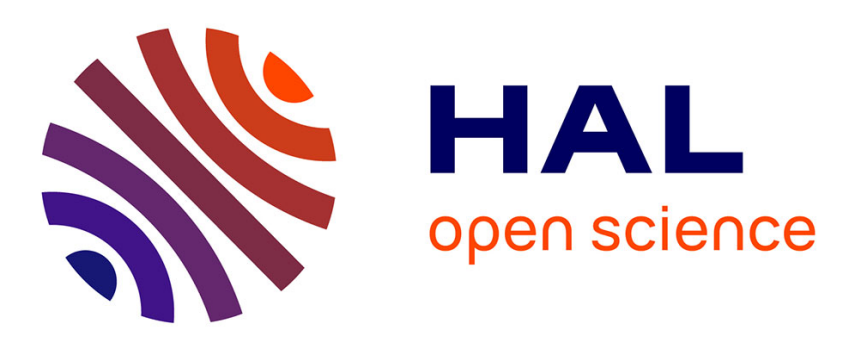

\title{
Integrated energy management of a plug-in electric vehicle in residential distribution systems with renewables
}

Farid Khoucha, Mohamed Benbouzid, Yassine Amirat, Abdelaziz Kheloui

\section{- To cite this version:}

Farid Khoucha, Mohamed Benbouzid, Yassine Amirat, Abdelaziz Kheloui. Integrated energy management of a plug-in electric vehicle in residential distribution systems with renewables. IEEE ISIE 2015, IEEE, Jun 2015, Buzios, Brazil. pp.717-722, 10.1109/ISIE.2015.7281557 . hal-01213103

\author{
HAL Id: hal-01213103 \\ https://hal.science/hal-01213103
}

Submitted on 7 Oct 2015

HAL is a multi-disciplinary open access archive for the deposit and dissemination of scientific research documents, whether they are published or not. The documents may come from teaching and research institutions in France or abroad, or from public or private research centers.
L'archive ouverte pluridisciplinaire $\mathbf{H A L}$, est destinée au dépôt et à la diffusion de documents scientifiques de niveau recherche, publiés ou non, émanant des établissements d'enseignement et de recherche français ou étrangers, des laboratoires publics ou privés. 


\title{
Integrated Energy Management of a Plug-in Electric Vehicle in Residential Distribution Systems with Renewables
}

\author{
Farid Khoucha ${ }^{1,2}$, Mohamed Benbouzid ${ }^{2}$, Yassine Amirat $^{3}$ and Abdelaziz Kheloui ${ }^{1}$ \\ ${ }^{1}$ Ecole Militaire Polytechnique, UER ELT, Algiers, Algeria \\ ${ }^{2}$ University of Brest, EA 4325 LBMS, Brest, France \\ ${ }^{3}$ ISEN Brest, EA 4325 LBMS, Brest, France \\ Mohamed.Benbouzid@univ-brest.fr
}

\begin{abstract}
According to innovation in grid connected transportation industry and with ever increasing concerns on environmental issues and clean energy, electric vehicles (EVs) and hybrid electric vehicles (HEVs) with low noise, zero emission, and high efficiency have attracted more and more attention of researchers, governments and industries, they are becoming the most likely fleets to replace gasoline vehicles in future power systems. In addition to the approved advantages for transportation, EVs have the potential to provide other benefits within the connected residential distribution to micro-grids and smart grids as part of a vehicle-to-grid (V2G) system, knowing that in future systems residential distribution can be seen as an energy resource with decentralized and autonomous decisions in the energy management called smart house or prosumer. They can participate effectively in helping to balance supply and demand by valley filling and peak shaving. The EV battery can be charged during low demand and the stored power can be fed power back into the micro-grid during high-demand periods, providing a spinning reserve to dump short power demand changes. V2G may also be used to buffer renewable energy sources, such as photovoltaic generators, by storing excess energy produced during illumination periods, and feeding it back into the grid during high-load periods, thus effectively stabilizing the intermittency of solar power. In this context, this paper describes an energy management system for a smart house based on hybrid PV-battery and V2G.
\end{abstract}

Keywords-Vehicle-to-grid (V2G), vehicle-to-home (V2H), residential distribution, smart house, balance supply and demand.

\section{INTRODUCTION}

To deal with the global energy crisis and environmental pollution, it is becoming necessary to integrate renewable energy generation such as solar power, wind power and hydroelectric Power into the existing power grid. Meanwhile, hybrid electric vehicles (HEVs) and electric vehicles (EVs), particularly the plug-in electric vehicles (PEVs), for green transportation have attracted increasing attention [1], [2]. Because of the intermittent nature of solar power, large-scale integration of solar power poses a challenge on the power grid in both transient and steady states. Vehicle-to-grid (V2G) operation can help address the challenges by acting as a mobile energy storage device [3]. A large number of EVs were considered adjustable generators, which were used to provide power to minimize both cost and emission. However, the characteristics of the $\mathrm{V} 2 \mathrm{G}$ power and the availability of EVs were not adequately considered in the $\mathrm{V} 2 \mathrm{G}$ optimization system. Then, the study and analysis of the integration of an electric vehicle into the micro-grid energy management was performed, but unfortunately faced with the limitations imposed on the $\mathrm{V} 2 \mathrm{G}$ power due to the characteristics of $\mathrm{EV}$ batteries [4].

Moreover, several techniques have been proposed and implemented to ensure optimal energy transfer in the V2G system to maximize the benefit of V2G [5]. However, there were shortcomings that the power flow of EVs was unidirectional, the charging rate was fixed at the maximum limit, and the optimal solution was the selected charging intervals during the plug-in period.

With the ever-increasing popularity of EVs [6] the frequency regulation provided by $\mathrm{V} 2 \mathrm{G}$ operation has been actively studied. Several studies have focused using electric vehicles of different sizes and configurations for the control of the frequency and voltage fluctuations on the grid with connected V2G system [7]. Moreover, EVs could provide various auxiliary services such as the energy scheduling for load leveling [8], the minimization of the ratio between time and charging cost [9], and the spinning reserve [10]. Although a variety of regulation services are suggested for V2G energy management, they are still far from being unique and optimal solution.

This paper deal with the development of a wide control structure for an advanced smart house connected to a microgrid, which includes renewable energy sources, battery and an $\mathrm{EV}$, so that the V2G power can be properly deployed. The scale of distributed generators and the EV penetration degree are assumed for illustration. Nevertheless, they can readily be modified and adapted for other case studies. 


\section{System CONFIGURATION}

The residential micro-grid or Smart House (SH) considered for this work corresponds to one household and it is described in Fig. 1. The distributed energy resources considered are a micro-turbine, an active generator (photovoltaic module associated with battery), and the battery of a PEV. At this home, the home energy management system (HEMS) communicates with the different devices constituting the load and all the energy sources by smart meters. Understanding each device condition and information on changes in power consumption, control of different devices, and energy management become easier using smart meters and sensors,.

The $\mathrm{SH}$ has photovoltaic (PV) system as a renewable energy source (this source is very effective in reducing energy consumption especially in Algeria with many isolated areas). This hybrid generator system is also used to perform standalone operation when a perturbation affects the electrical network. The power generation system of the $\mathrm{SH}$ is composed by the PV system, medium-capacity battery and plug-in electrical vehicle (PEV).

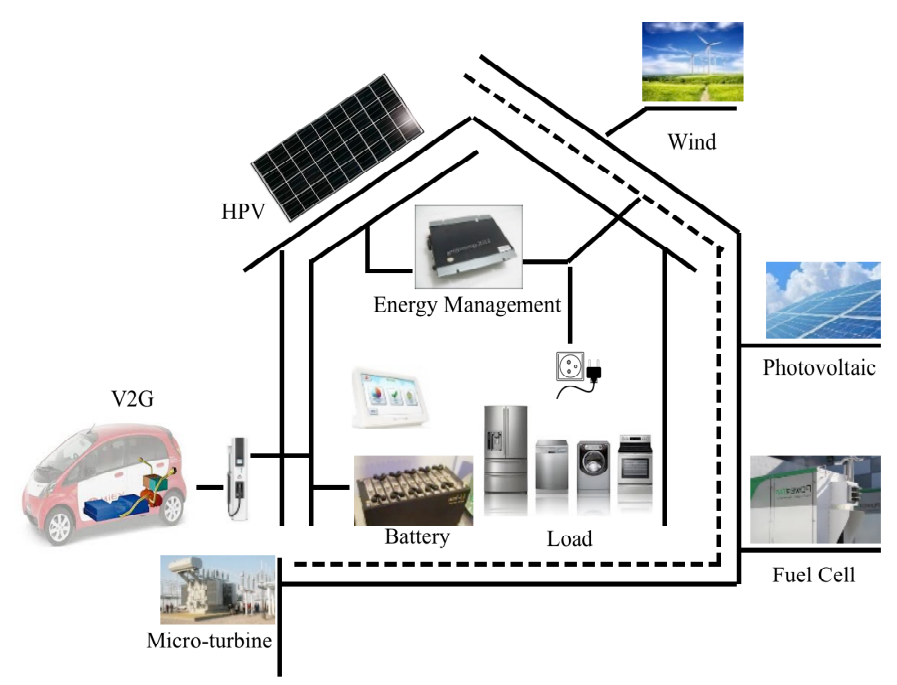

Fig. 1. Smart home scheme with V2G system.

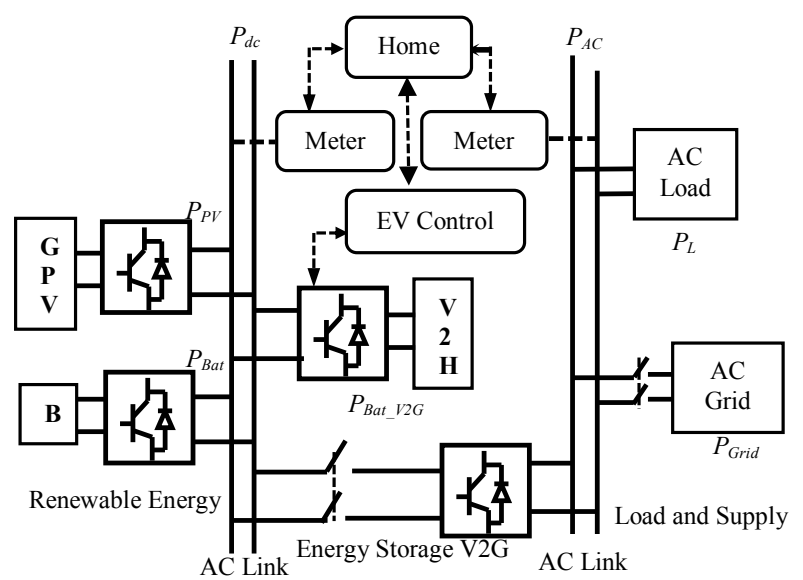

Fig. 2. Converter network for the smart home with V2G system.
The use of medium-capacity battery can be expected to reduce the cost and installation space as compared to the use of high capacity battery. A standard smart house is required a battery capacity of $8 \mathrm{kWh}$ to ensure the necessary power at home per day during the blackout.

The configuration of the simulation model is shown in Fig. 2. The PV system is connected to the DC-DC converter, which can perform the MPPT control. Similarly, the battery is connected to the DC-DC converter, which can perform the DC link voltage control around $400 \mathrm{~V}$. The EV is also connected to the DC-bus by a DC-DC converter. This adopted connection scheme allows reducing power conversion stages and therefore leads to an efficient energy management. The inverter converting DC power sources to AC power are connected to single-phase utility of $220 \mathrm{~V}$ and $50 \mathrm{~Hz}$.

\section{EV Home Charging Process}

An electric vehicle in $\mathrm{V} 2 \mathrm{G}$ process is different from other devices used for housing power regulation service, peak shaving and valley filling mainly for its dependence on batteries. Battery life is very influenced by the number of cycles, depth of discharged, charge/discharge rates and other factors [11-12]. Users of electric vehicles usually require the batteries to be fully charged in the shortest period of time as possible to increase the vehicle's autonomy. Both battery life and charging time are therefore major constraints for electric vehicle plugged to the grid. The maximum time for recharging a battery should be set as a tradeoff between the need of having a quick recharge as required by the user, and participating in power regulation service as desired by the energy manager for the connected home to a smart micro-grid. One could envisage incentive schemes that encourage EV users to allow the participation of their vehicles in the $V 2 G$ system with the two configurations Vehicle to home (V2H) and home to vehicle $(\mathrm{H} 2 \mathrm{~V})$. The $\mathrm{V} 2 \mathrm{G}$ system could also include a prioritizing system that considers the history of the battery usage when the vehicle is disconnected to set an appropriate charging time.

In addition to battery and consumer constraints, the power regulation service like peak shaving and valley-filling V2G system needs to meet the following constraints.

\section{A. Constraints on the Power of EVS Involved in the V2G System}

$\left\{\begin{array}{l}\left|y_{i}\right| \leq a_{i} \quad a_{i} \succ 0 \\ \left|y_{i}\right| \leq\left|b_{i}\right| \quad b_{i} \prec 0 \\ \left|y_{i}\right| \leq\left|z_{i}(t)-x_{i}(t)\right|\end{array}\right.$

Where $a_{\mathrm{i}}$ is a positive number equal to the maximum value of the total charge power from the micro-grid to the plugged EVs, and is $b_{i}$ is a negative value equal to the maximum value of the total discharge power from the EV connected to the micro-grid. $x_{i}(t)$ is the forecast load value, determined from 
historical power usage and $z_{i}(t)$ is the target load value, derived from the states of the load and vehicle.

This constraint limits the value of $y_{i}(t)$ to be less than the maximum service capability of EVs, depending on the vehicle ability to overcome the requirement of the traffic, and the power of the load in the area of vehicle use. However, the value of $y_{i}(t)$ cannot be more than the supply and demand of the grid.

B. Constraints on the Vehicle Battery during Charging and Discharging Modes

$\left\{\begin{array}{l}0 \leq C_{i}^{c h} \leq C_{c \max } \\ 0 \leq C_{i}^{d i s} \leq C_{d \max } \\ -I_{c \max } \times V_{i}^{c h} \leq P_{i} \leq I_{d \max } \times V_{i}^{d i s}\end{array}\right.$

Where $C_{i}^{c h}$ is the charge ratio, $C_{i}^{\text {dis }}$ is the discharge ratio, $C_{c \max }$ is the available maximum charge ratio, $C_{d \max }$ is the available maximum discharge ratio, $V_{i}^{c h}$ is the charge voltage, $V_{i}^{d i s}$ is the discharge voltage, $I_{c \max }$ is the charge current within the maximum charge ratio $C_{c \max }, I_{d \max }$ is the current within the maximum discharge ratio $C_{d \text { max }}$, and $P_{i}$ is the $\mathrm{EV}$ available power.

The battery limits the current and power of each connected EV. The maximum charge and discharge current cannot be more than the charge current $I_{c \max }$ and the discharge current $I_{d \max }$. Besides the current, the power limit relies on the voltage of the EV battery under this charge and discharge current.

\section{Constraints on the EV Battery Capacity}

$$
\left\{\begin{array}{l}
\Delta Q_{i}^{\max }=\left(S O C_{\max }-S O C_{\min }\right) Q_{e} \\
0 \leq \Delta Q_{i}^{c h} \leq\left(S O C_{\max }-S O C_{i}\right) Q_{e} \\
0 \leq \Delta Q_{i}^{d i s} \leq\left(S O C_{i}-S O C_{\min }\right) Q_{e}
\end{array}\right.
$$

Where $S O C_{i}$ is the real-time capacity state, $S O C_{\max }$ and $S O C_{\min }$ are the maximum and minimum value of $S O C$, respectively. $\Delta Q_{i}^{\max }, \Delta Q_{i}^{c h}, \Delta Q_{i}^{d i s}$ and $Q_{e}$ are the maximum available capacity, the available charge capacity, the available discharge capacity and the rated capacity of the EV battery, respectively.

To ensure the battery life and energy efficiency, the range of $S O C$ is limited. The maximum available capacity is decided by the rated capacity and the difference between, $S O C_{\max }$ and $S O C_{\min }$.

EV user-setting constraints are also important factors that affect the capability of the EV to participate in V2G system to power supply and demand regulation. For transportation, EV should satisfy the driving demand first, which means that the EV user may set the upper and lower limits of SOC and the special period in which the EV can be involved in $\mathrm{V} 2 \mathrm{G}$ system, in this case, EV even if plugged, the battery can only be charged for the planned trip by the user (H2V mode). The EV user set parameters shown in Fig. 3 can be represented as follows:

$$
S O C_{\min }^{*} \leq S O C_{i}^{*} \leq S O C_{\max }^{*}
$$

Where $S O C_{\min }^{*}$ and $S O C_{\max }^{*}$ are the lower and upper limits of $S O C$ indicated by the manufacturer or set by the user, respectively. To ensure the safety and increase the life of the EV battery, $S O C_{\min }^{*}$ cannot be lower than $S O C_{\text {min }}$, and also $S O C_{\max }^{*}$ cannot exceed $S O C_{\max }$. When the $\mathrm{EV}$ is plugged to the grid, the state of $\mathrm{EV}$ is decided by these constraints. If $S O C_{i}$ is lower than $S O C_{\text {min }}^{*}$, the EV needs to be preferably in the charge state (home to vehicle mode). If $S O C_{i}$ is higher than $S O C_{\max }^{*}$, then the EV can enter into the discharge state (vehicle to home mode).

If $S O C_{i}$ is between $S O C_{\min }^{*}$ and $S O C_{\max }^{*}$, the $\mathrm{EV}$ operating state represented in Fig. 3 is decided by the energy management system according to the home power and user requirements.

\section{House ENERGy MANAGEMENT SyStems}

In this paper only, a single house or prosumer and a gas micro-turbine are considered in this micro-grid (Fig. 1). The House Energy Management (HEM) integrates three functions: a load manager, an advanced meter, and a local energy management. The load manager allows customers automatically planning the use of home devices (enable and disable) on the basis of low price, critical schedules and depending on the profile of the total consumption, such as uninterrupted supply of critical loads, time programmable use, etc. Moreover, it can reduce a part of the home power demand when the grid is under stress by disconnecting the accessible controllable loads [13]. An advanced meter feeds the local HEM as well as the load manager. Moreover, the utility is able to ping the meter. Photovoltaic panels are associated with a storage system which includes a set of batteries as a long-term storage device [14] and a battery of $\mathrm{V} 2 \mathrm{G}$ as a dynamic regulator of power when the vehicle when is plugged-in and the state of charge of the battery allows it (Fig. 4).

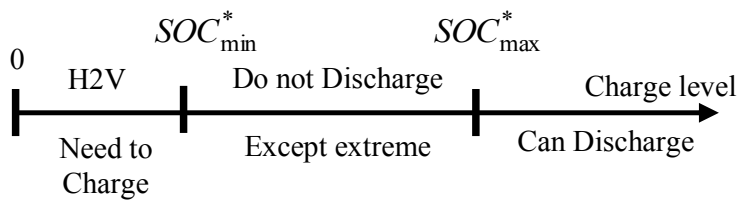

Fig. 3. Battery charging and discharging strategy. 


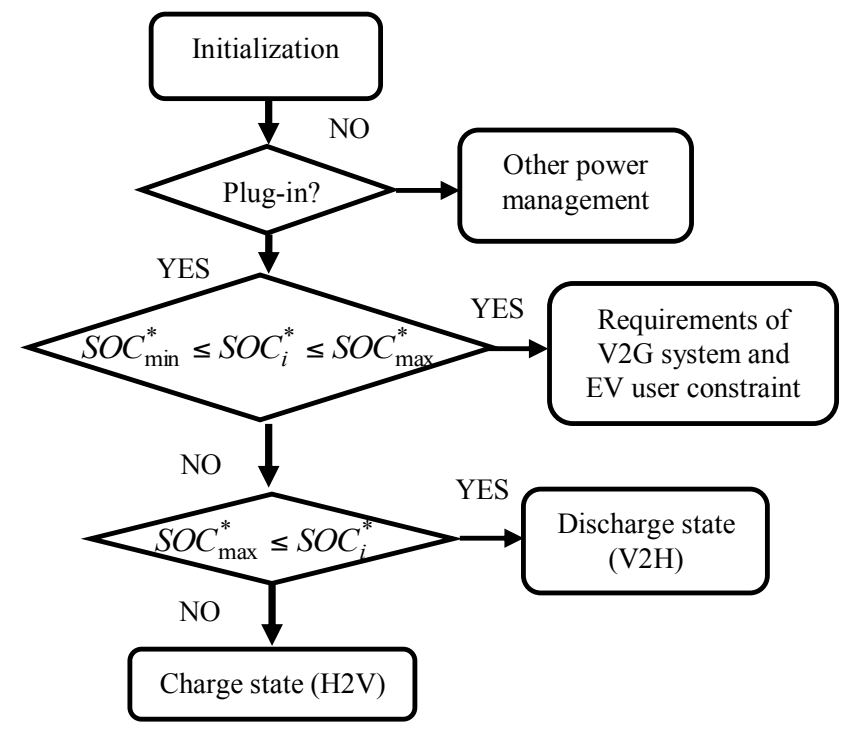

Fig. 4. Energy management of the V2G control system.

The interesting aspect of this hybrid generator is that it is able to deliver a prescribed power level $\left(P_{H P_{-} r e f}\right)$ like a conventional generator (for example, a gas micro-turbine). The local energy management thus allows the use of PV energy according to the grid operator requirement and also at times when the sun is not shining.

In this case, the home batteries are required to provide the necessary power. This concept is called an active generator to make a difference with a conventional generator based only photovoltaic panels. Excess PV energy is stored in home batteries and EV Battery for use when needed, knowing that the vehicle is rarely plug-in to the home during the day. The HEM gives an intelligent control to facility to the grid operators and to allow faster adjustments to conditions and gives more flexibility to reroute power in a certain offered margin. Photovoltaic panels provide electrical power only during the day with a power peak around the midday. Meanwhile, vast production variations may occur.

According to the weather forecasting and the historic database of PV power, an ahead-approximated PV power prediction profile $\left(\hat{P}_{P V}\right)$ can be used. The load forecasting is also ahead-approximated the energy management. Based on historic electrical power production demands, the behavior of the loads can be forecast and estimated.

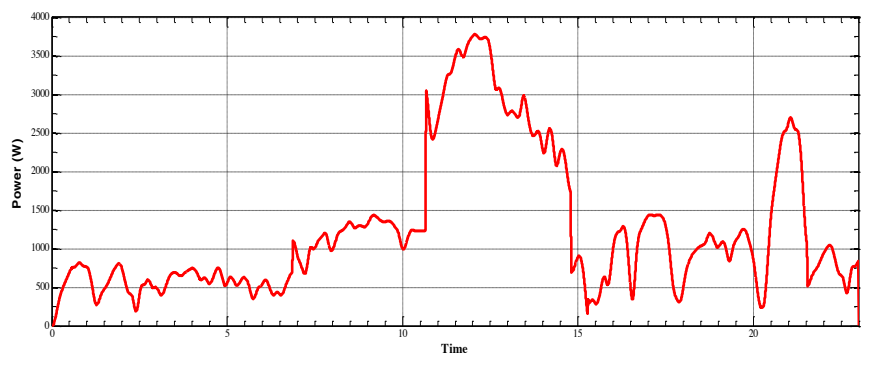

Fig. 5. A day household consumption prediction.
Several factors influence the load in the electrical network: the weather situation (temperature, cloud coverage, etc.), economic activity (huge modifications of load forecasting are necessary during the holiday periods). An approximate load forecasting profile $\left(\hat{P}_{\text {Load }}\right)$ is given in Fig. 5.

In this studied case, three power sources are considered: a PV-based active generator, a V2G system and a gas microturbine. Because of the renewable energy benefits (less gas emission and low operating cost), the PV-based active generator is considered as the main source, the gas microturbine and EV Battery are considered as a backup sources for the missing energy [15]. The objective is to set a minimum charging/discharging cycle for batteries every day. The depth of the discharge is maintained between $10 \%$ and $80 \%$ during normal operation to increase the battery lifetime. Here, the storage and EV battery capacity are $8 \mathrm{kWh}$ and $5 \mathrm{kWh}$, respectively.

According to daily predictions of the available power, energy from the active generator, the EV battery energy when electric vehicle is plugged-in and the required power and energy of the loads $\left(P_{\text {Home }}\right)$, a power production planning for the prosumer $\left(P_{H P}\right)$ and for the micro-turbine $\left(P_{\text {Grid }}\right)$ must be determined. As no power is available from PV panels during the night and the electric vehicle usually disconnected during the day, power references can be calculated separately for the night and for the day.

In the day and when the EV is disconnected (Fig. 6), two cases are considered.

If the available PV energy added with the minimum gas turbine energy is less than the demanded load energy $\left(\hat{E}_{P V}+\hat{E}_{\text {Grid_min }}<\hat{E}_{\text {Home }}\right)$, the PV panels can work with a maximum power point tracking (MPPT) algorithm, and all PV power is injected in the grid. The gas micro-turbine has to generate the missing power.

$\left\{\begin{array}{l}P_{H P_{-} \text {ref }}=\hat{P}_{P V} \\ P_{\text {Grid_ref }}=\hat{P}_{\text {Home }}-P_{H P_{-} r e f}\end{array}\right.$

Otherwise, the available PV energy added to the minimum gas turbine energy is more than the demanded load energy $\left(\hat{E}_{P V}+\hat{E}_{\text {Grid_min }}>\hat{E}_{\text {Home }}\right)$. Priority is then given to the renewable energy for the electrical production so that the gas micro-turbine works with minimum power and the active generator power is limited to the missing power.

$\left\{\begin{array}{l}P_{\text {HP_ref }}=\hat{P}_{\text {Home }}-P_{\text {Grid_min }} \\ P_{\text {Grid_ref }}=P_{\text {Grid_min }}\end{array}\right.$

The energy management during the night depends on the available energy from batteries in homes and V2G battery (Fig. 7). This energy can be estimated or communicated by the HEM. Two cases are also distinguished. For both cases, the batteries in home have to be discharged in order to be ready 


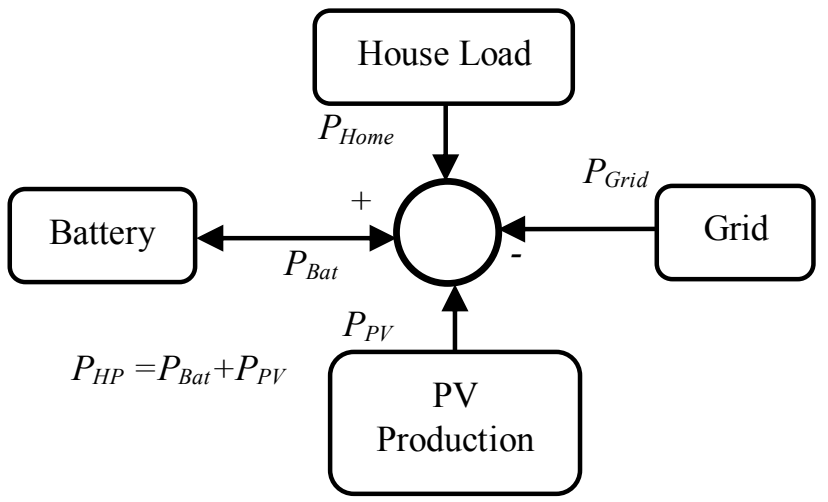

Fig. 6. Power distribution when PEV is not connected to home.

Fig. 7.

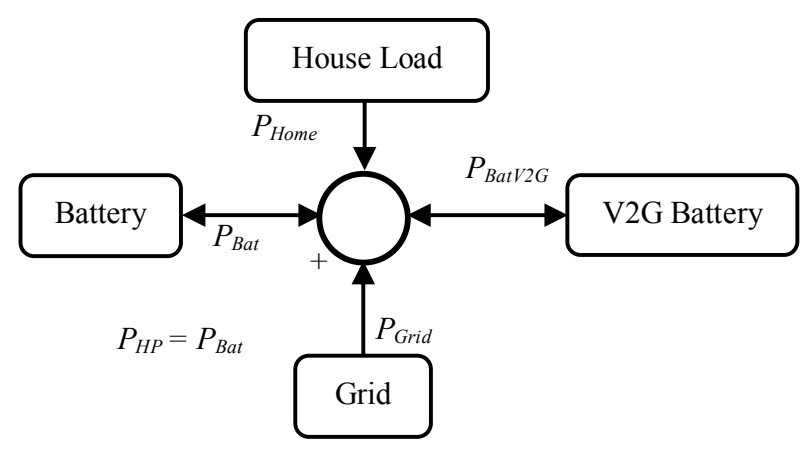

Fig. 8. Power distribution when PEV is connected to home.

for charging the next day and the EV battery must be fully charged for the trip planned by the user.

The three cases for the night operation are related to the EV connection as follow:

During heavy energy demands and if the available stored energy in both home and EV battery added to the minimum gas turbine energy is more than the demanded energy from the loads, priority is given to the active generator for the electrical production since it has enough previously stored energy from PV panels.

The gas turbine will work with minimum power and the EV is operating in $\mathrm{V} 2 \mathrm{H}$ :

$\left\{\begin{array}{l}P_{H P_{-} r e f}=\hat{P}_{\text {Home }}-P_{\text {BatV } 2 G}-\hat{P}_{\text {Grid }} \\ P_{\text {Grid_ref }}=P_{\text {Grid_min }}\end{array}\right.$

And during the period of reduced consumption, the EV is operating in $\mathrm{H} 2 \mathrm{~V}$ mode and the $\mathrm{EV}$ battery is added to different house loads:

$\left\{\begin{array}{l}\hat{P}_{\text {Home_ref }}=\hat{P}_{\text {Home }}+P_{\text {BatV } 2 G} \\ P_{H P_{-} r e f}=\hat{P}_{\text {Home }}-\hat{P}_{\text {Grid }} \\ P_{\text {Grid_ref }}=P_{\text {Grid_min }}\end{array}\right.$
Otherwise, the stored battery energy added with the minimum gas turbine energy is less than the demanded energy from the loads. Then, the power reference of the active generator is calculated in order to discharge the home batteries, and the gas turbine must generate the missing power and power required to charge the EV battery under the constraints imposed in section IV. In this case the EV is operating in $\mathrm{H} 2 \mathrm{~V}$ mode.

$$
P_{\text {Grid_ref }}=P_{H P}-\hat{P}_{\text {Home }}-P_{\text {BatV } 2 G}
$$

\section{Case Study Simulation Results}

This section describes an example of a 1-day simulation. The vehicle is assumed to be pure electric vehicle and the EV driver leaves home at 6.00 am to go to the work (case of Algiers city in Algeria) and finishes at $7.00 \mathrm{pm}$ without charging during working time. This simulation shows a 24 hours pattern.

According to the objective of the intelligent house energy management that is applied to this scenario, as it is shown in Fig. 9, vehicle battery is charged at the low-load hours to flatten the load profile curve (Fig. 10), this charging is also decided if the available PV power in the MPPT is higher than the requested power reference and if batteries are not full.The state of charge has to be estimated and compared with the maximum value.

Furthermore, at peak hours, vehicle battery starts to discharge to reduce the peak value of loads. The uncertainty of photovoltaic system is compensated by the micro-turbine in the day and replaced by the home battery in the night (Fig. 11).

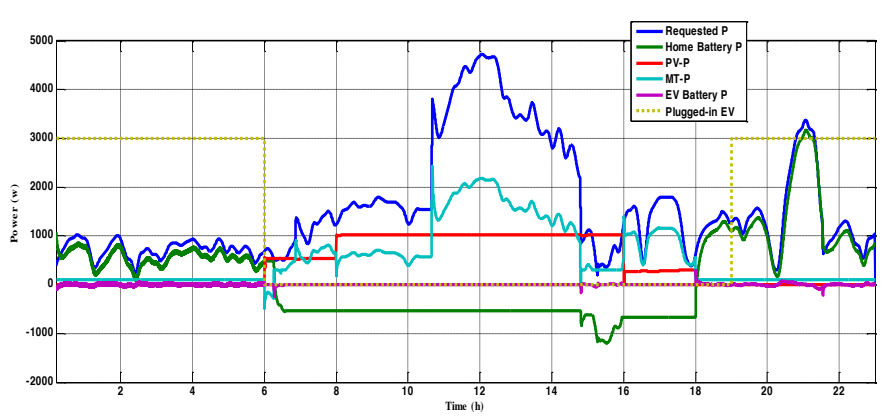

Fig. 9. Energy management according to the power planning in the intelligent house.

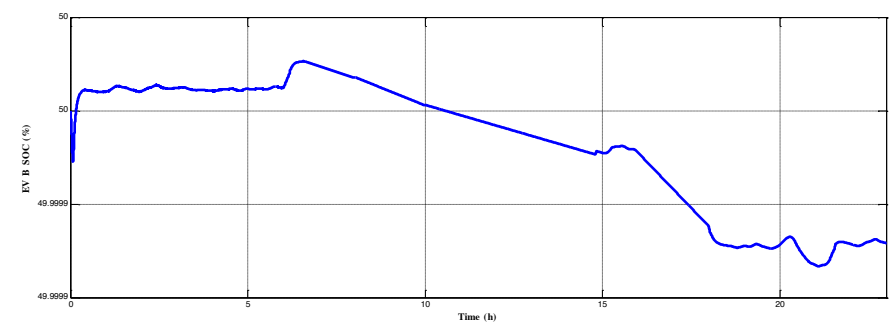

Fig. 10. Daily EV battery SOC variation. 


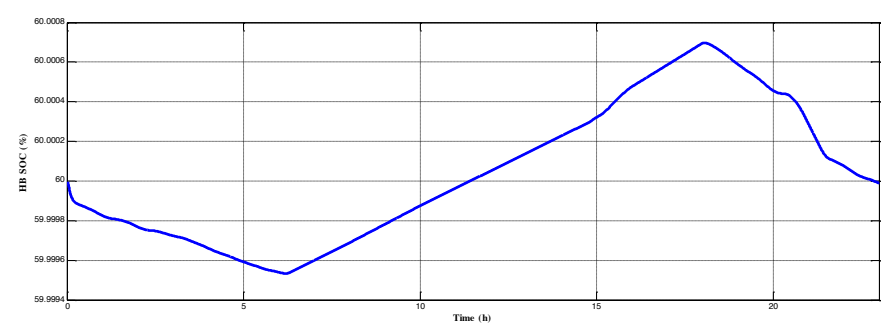

Fig. 11. Daily home battery SOC variation.

\section{CONCLUSION}

The energy management of houses and stand-alone and consumers and/or sites connected has strong relevance in the future power systems, mainly in micro-grids and smart grids operation context. This paper focuses on energy management methodology in real-time to obtain new solutions for the domestic consumers with plugged-in electric vehicle (V2G), in order to contribute with new approaches for the power systems. It is important to identify, within domestic consumers, the influence that load has in power consumption, and how the management methodology influences the total consumption of the domestic consumer taking into account the grid, house conditions, weather and the requirements of the EV users. In this paper a dynamic energy management was proposed to meet house demand within according to the different dynamics and nature of sources.

Simulation have been carried-out for a typical smart home daily consumption profile with two power peaks around the midday when the vehicle is disconnected and at $9.00 \mathrm{pm}$. The total energy required by the load and to recharge the home battery was mostly carried by solar panels (MPPT). The energy difference was supplied by the micro-turbine, so the peak power consumption has been avoided from the grid. The home battery was charged after the peak power and any extra energy was used during this peak power. To complete the control strategy a function related to the state of charge of the EV battery has been implemented. To limit both home and EV batteries degradation, charging and discharging cycles were limited by using a minimum and maximum charge limits. This power management strategy could also be applied when EV is not available, which means $\mathrm{V} 2 \mathrm{H}$ would not be considered when EV is not at home. Based on the achieved simulation results, it is obvious that an energy management scheme with V2G would reduce the peak energy consumption with better management of batteries state of charge.

\section{REFERENCES}

[1] C.C. Chan, A. Bouscayrol and K. Chen, "Electric, hybrid, and fuel cell vehicles: architectures and modeling," IEEE Trans. Vehicular Technology, vol. 59, n², pp. 589-598, February 2010.

[2] A. Khaligh and Z. Li, "Battery, ultracapacitor, fuel cell and hybrid energy storage systems for electric, hybrid electric, fuel cell and Plug-In hybrid electric vehicles," IEEE Trans. Vehicular Technology, vol. 59, $\mathrm{n}^{\circ} 6$, pp. 2806-2814, July 2010.

[3] C. Liu, K. T. Chau, D. Wu, and S. Gao, "Opportunities and challenges of vehicle-to-home, vehicle-to-vehicle and vehicle-to-grid technologies," Proc. of IEEE, vol. 101, no. 11, pp. 2409-2427, November 2013.

[4] B. Lunza, Z. Yana, J.B. Gerschlerb and D. Sauera, "Review of the impact of vehicle-to-grid technologies on distribution systems and utility interfaces," Energy Policy Journal, vol. 46, pp. 511-519, July 2012.

[5] N. Rotering and M. Ilic, "Optimal charge control of plug-in hybrid electric vehicles in deregulated electricity markets," IEEE Trans. Power Systems, vol. 26, n³, pp. 1021-1029, August. 2011.

[6] S. Han, S. Han, and K. Sezaki, "Estimation of achievable power capacity from plug-in electric vehicles for V2G frequency regulation: Case studies for market participation," IEEE Trans. Smart Grid, vol. 2, n4, pp. 632-641, December. 2011.

[7] S. Han, S. Han, and K. Sezaki, "Development of an optimal vehicle-to grid aggregator for frequency regulation," IEEE Trans. Smart Grid, vol. $1, n^{\circ} 1$, pp. 65-72, February 2010.

[8] B. Kim, S. Ren, V. Schaar and J. Lee, "Bidirectional energy trading and residential load scheduling with electric vehicles in the smart grid," IEEE Journal on Selected Areas in Communications, vol.31, n7, pp. 1219-1234, July. 2013.

[9] J. Ding, K. R. Yu, and Y. Liu, "Optimal PHEVs charging management by tradeoff between utility cost and user satisfaction," in Proceedings of the 2013 CHINACOM, Guilin (China), pp. 936-941, August 2013.

[10] V.V. Viswanathan and M. Kintner-Meyer, "Second use of transportation batteries: Maximizing the value of batteries for transportation and grid services," IEEE Trans. Vehicular Technology, vol. 60, n7, pp. 29632970, September 2011.

[11] A. Benrabah, F. Khoucha, O. Herizi, M.E.H. Benbouzid and A. Kheloui, "FC/battery power management for electric vehicle based interleaved DC-DC boost converter topology," in Proceedings of the 2013 EPE ECCE Europe, Lille (France), pp. 1-6, September 2013.

[12] Z. Wang and S. Wang, "Grid power peak shaving and valley filling using vehicle to grid systems," IEEE Trans. on Power Delivery, vol. 28, n³, pp. 1822-1829, July 2013.

[13] A.R. Boynueqri, B. Yagcitekin, M. Baysal, A. Karakas and M. Uzunoglu, "Energy management algorithm for smart home with renewable energy sources," in Proceedings of the 2013 IEEE POWERENG, Istanbul (Turkey), pp. 1753-1758, May 2013.

[14] H. Kanchev, Di Lu, F. Colas, V. Lazarov, and B. Francois, "Energy management and operational planning of a microgrid with a PV-based active generator for smart grid applications," IEEE Trans. Industrial Electronics, vol. 58, n¹0, pp. 4583-4595, October 2011.

[15] M. Yilmaz and P.T. Krein, " Review of the impact of vehicle-to-grid technologies on distribution systems and utility interfaces," IEEE Trans. Power Electronics, vol. 28, n¹2, pp. 4673-4689, December 2013. 